\title{
Organizing Employees to Observe the Results of QC Efforts and
}

\section{Inspection of Technological Innovation Projects}

\author{
Kai Xue ${ }^{1, a}$, Shouchen $\mathrm{Xu}^{2, \mathrm{~b}}$, Xilin Zhang ${ }^{3, \mathrm{c}}$, Xiaojuan Han ${ }^{4, \mathrm{~d}}$ \\ 1. State Grid Jilin Electric Power Company Limited Training Center, Changchun, Jilin 130022, \\ China \\ 2. State Grid College of Management, Beijing, 100085, China \\ 3. State Grid Jilin Electric Power Company Limited Changchun Power Supply Company, \\ Changchun, Jilin 130021, China
}

4. Department of Control and Computer Engineering University of North China Electric Power, Beijing, 102206, China

$$
\begin{aligned}
& \text { a381093267@qq.com, 'b shouchen-xu@sohu.com, }{ }^{\text {c9 } 985222805 @ q q . c o m, ~} \\
& \text { d1747860586@qq.com }
\end{aligned}
$$

Keywords: QC, technological innovation, on-the-job personnel, job training

\begin{abstract}
In order to develop a large number of grassroots-level technical innovation backbone personnel of power enterprises, the paper discusses the purposes, targets, processes and expected effects of on-the-job training programs organized to provide employees with an opportunity to observe the results of QC efforts and the inspection of technological innovation projects. The requirements of the Mass Entrepreneurship and Innovation Program and the lack of technical innovation backbone in grassroots-level power companies indicate the necessity and urgency of adopting the method described in this paper.
\end{abstract}

\section{Introduction}

To promote the Mass Entrepreneurship and Innovation Program, it is necessary to train a large number of grassroots-level technical backbone personnel to support technological innovation in the power sector, to meet the demand of the global energy network, and to build an innovation-oriented science superpower.

However, resource distribution in quality control and technological innovation is imbalanced and in the vast majority of grassroots-level organizations there are only a few employees assigned to positions in relation to QC and technological innovation, leading to the lack of technical backbone personnel. Because the majority of the staff lacks knowledge on theories, methods, processes and specific practices related to QC and technological innovation, it is difficult to put QC and technological innovation visions into action. Some young employees with ambition have no opportunity to learn skills and acquire knowledge, which makes it difficult for them to play a bigger role in this area.

Literature [1]-[7] examines on-the-job training of employees. The paper discusses the issue of cultivating grassroots-level technical innovation backbone personnel in the electric power sector through the observation of QC results and the inspection of technological innovation projects.

Release of QC results and the inspection of technological innovation projects is the sum-up step of the whole process of QC and technological innovation activities. The scope and implementation process of QC and technological innovation activities are reflected in the released 
results and at the inspection stage. Providing employees with opportunities to observe QC results and the inspection of technological innovation projects is an effective and efficient means to train a large number of grassroots-level technical innovation backbone personnel for the electric power sector.

2. Purpose of Observing the Results of QC Efforts and the Inspection of Technological Innovation Projects

Demonstration for on-the-job training is a very effective teaching activities.Through the demonstration of a practical case, participants will be aware the various key links of the actual case.Learning the theory, methods and practice of the case, understanding the bottleneck problems and solutions. Demonstration has the characteristics of intuitive, practical and the students are willing to accept. The effect of demonstration teaching is often better than the faculty classroom teaching,give students a more profound impression.

QC and technological innovation are two main technical research activities, is the effective carrier of innovation.All sorts of problems associated with technology, generally can be solved by these two technical research activities.Therefore, popularize knowledge of QC and technical innovation at the grassroots level of electric power enterprises and focus on training in-service personnel QC and technical innovation ability,will play an active role to promote the "Mass Innovation" .

In the past, there are three types of personnel participate in QC results release and technical innovation projects acceptance :the first is project team members, the second category is expert panel reviewers, and the third category is organizer management personnel.There will be a small number of people volunteered to participate in QC results conference, but the technical innovation project participants are generally the above three categories of personnel.

After observing the results of QC efforts and the inspection of technological innovation projects, participants will be able to understand major problems in and methods and processes of QC and technical innovation activities and know what are their duties and how and when to perform their duties when they are assigned to complete jobs related to QC and technological innovation independently.

\subsection{Major Problems in QC and Technological Innovation}

It is imperative to solve the bottlenecks in QC and technological innovation processes, to improve key technologies, efficiency and technical reserves of companies through QC and technological innovation, to translate QC and technological innovation into productivity, to help grassroots-level technical backbone personnel improve their creativity and develop problem discovering, analyzing and solving skills, to create a positive and progressive work environment to advocate a hard-working culture.

2.2 QC and Technological Innovation Processes and Methods

QC activities are flexible and diverse activities that utilize new technologies, theories and methods as well as recommended practical analyzing tools to address minor problems in production activities.

Technological innovation mainly aims at addressing pressing issues and proposing innovative technological ideas and putting them into action in accordance with national or industrial technological innovation policies. A complete technological innovation activity can be divided into the following steps: launching a technological innovation project, setting up a technological 
innovation task group, preparing project application materials, selecting partners, negotiating business contracts, technical agreements and matters related to technical liaison meetings, developing a project implementation plan, managing project progress, formulating a technical security plan, filling out work order sheets, installing and configuring equipment, troubleshooting, submitting patent applications, writing a project paper, registering software copyrights, preparing materials for inspection, organizing an inspection meeting, presenting reports and Q\&A at the inspection meeting, preparing materials to apply for technological innovation registration and translating technological innovation into practice.

\section{Participants}

Electric power companies may provide new recruits, employees who have completed 2-5 years of service and those who are willing to obtain QC and technological innovation knowledge with an opportunity to observe QC results and the inspection of technological innovation projects. Reserve experts can also participate in these activities at their own will.

\section{Process}

4.1 Submitting an application to the head of the organization that is responsible for releasing QC results and inspecting technological innovation projects

An application should be submitted to the head of the organization that is responsible for releasing QC results and inspecting technological innovation projects, specifying the number of participants and purposes.

Due to capacity of the conference room where the event takes place, the number of people participating in the event may be restricted, so observation activities must be carried out in an organized manner.

4.2 Introducing the highlights of the event to the participants prior to the event

The trainer or relevant personnel should introduce the highlights of the event to the participants as a preview lesson.

With respect to the release of QC results, participants should understand how the QC results will be released, focusing on using PowerPoint to introduce how to choose a topic, conduct status quo investigation, determine the target value, analyze the cause, identify the key cause, develop countermeasures, improve the efficiency of implementation, get to know tools that are often used in QC activities, how to create a PowerPoint presentation to report QC results, and how to answer questions raised by the reviewers.

Materials for use at a technological innovation project inspection meeting generally include seven documents: work report, technical report, test report, economic benefit analysis report, user report, domestic and foreign technical comparison report and update report.

After the project team presents the report, they will answer the questions raised by experts.

Finally, an inspection opinion will be developed.

A central government-owned enterprise provides the specific format of work reports and PowerPoint presentations for use at the technological innovation project inspection meeting. A work report consists of project overview, research process and main tasks, the completion of task indicators, innovation and breakthroughs, the use of project funds, project personnel and division of labor, effect and impact of the project, self-evaluation, visions and recommendations for the application and transformation of the project and next step proposals. A PowerPoint presentation for use at the technological innovation project inspection meeting should include the following key 
elements: the implementation of the project, project progress, scope of research, research results and effectiveness, highlights of the results, summary and outlook, etc.

To prepare meeting materials in accordance with the standards laid out by the competent authority in charge of the inspection of technological innovation projects is of particular importance.

Having a better understanding of the agenda of QC and technological innovation project inspection meetings can help the participants put what they have learned into practice.

4.2 Making proper arrangements to provide employees with an opportunity to observe the results of QC efforts and the inspection of technological innovation projects

Upon approval of the competent authority, electric power companies should make proper arrangements to provide employees with an opportunity to observe the results of QC efforts and the inspection of technological innovation projects. Participants are required to follow the dress code, enter the venue in advance, mute their phones, and refrain from smoking, talking or walking around at the meeting.

If transportation and the number of participants are restricted, electric power companies may provide an opportunity to employees to observe the QC team demonstrating the release of results, so that more employees have access to opportunities to observe QC results and interact with the QC team in person.

4.3 Providing a platform for the participants to discuss what they have observed at the meeting

After the meeting, electric power companies should provide a platform for the participants to exchange views and deepen understanding. They may invite the person in charge of the release of QC results or members of the inspection team of technological innovation projects to discuss with employees face to face to help participants gain a better understanding of what they have observed. Participants are advised to write a report to record the observation, which will strengthen the training effect and be helpful for their future engagement in QC and technological innovation projects.

\section{5 .Expected Outcomes}

5.1 Participants will have a better understanding of the key steps of the QC and technological innovation process

PowerPoint presentations designed to demonstrate QC results or to be used at technological innovation project inspection meetings will offer a brief description of innovation activities in the whole process to help participants clearly understand the key steps of the QC and technological innovation process.

5.2 Participants will have a better understanding of main materials and forms of presentation used in the event

QC results are presented by using mainly PowerPoint files. The forms of presentation are not limited. Materials required for the release of QC results should be submitted to the review committee for approval prior to the release. With respect to the inspection of technological innovation projects, seven inspection reports will be presented within 30-45 minutes. Participants should learn how people in charge of releasing QC results or reporting the technological innovation projects present the reports at the meeting, answer questions put forward by the review or inspection committee so as to have a clear idea about how to prepare for the Q\&A session in advance.

5.3 Participants will have an idea of performing QC and technological innovation duties independently

Participants will get a glimpse of how QC results are published and how technological 
innovation projects are inspected, which will in turn motivate them to dedicate themselves to engaging in QC and technological innovation activities and give them an idea of how to perform QC and technological innovation duties independently in the future.

\section{Conclusions}

The Mass Entrepreneurship and Innovation Program requires electric power enterprises to cultivate a large number of grassroots-level technical innovation backbone personnel. In addition to technological innovation training programs, power enterprises should provide employees with an opportunity to observe QC results and the inspection of technological innovation projects, which is an effective method to train grassroots-level technical backbone personnel for the electric power sector.

\section{References}

[1] Zhang Xilin, Xu Shouchen, On Research and Practice of Building a Harmo Progr \& Pro Team with Technological Innovation as Management Media [C] 2nd International Conference on Management Science and Industrial Engineering, 2013, pp.514-518.

[2] Zhang Xilin, Xu Shouchen, Innovation Research on Learning from Lv Qingsen Activities by Grass-root Party Organizations [C] 2nd International Conference on Management Science and Industrial Engineering, 2013, pp.510-514.

[3] Zhang Xilin, Zhang Hui, Contest of Dispatch Departments in Power Supply Enterprises [J], China Electric Power Education, vol. 35, pp.243-244, 2010.

[4] Zhang Xilin, Xu Shouchen, Research on Innovative Training Methods for Frontline Employees in High-Technology Department of Power Enterprises and the Practices [C] 2nd International Conference on Management Science and Industrial Engineering, 2013, pp.518-521.

[5] Li Yiling, Zhang Xilin, Zhang Yan. Originality, Question Bank Construction and Practice of "Five-One" Theme Training [J]. China Electric Power Education, vol. 27, pp.229-231, 2010.

[6] Zhang Xilin, Yang Guiying, Liu Xiaowei. Training Management Experience of Power Dispatching Department of Power Supply Enterprises [J]. China Electric Power Education, vol. 29, pp.48-50, 2010.

[7] Zhang Xilin. The Inspiration Brought to us by Lv Qingsen [J]. Jilin Electric Power, vol. 12, pp.12-13, 2011. 